JURNAL ILMIAH KEBIDANAN IMELDA

Vol.7, No.1, Maret 2021, pp. 36-41

ISSN: 2597-7180 (Online), 2442-8116 (Print)

http://jurnal.uimedan.ac.id/index.php/JURNALKEBIDANAN

\title{
PENGARUH TEKNIK HYPNOBREASTFEEDING TERHADAP PENGELUARAN ASI PADA IBU NIFAS
}

\author{
Parida Hanum ${ }^{1}$, Ashariah Rukmana Ritonga ${ }^{2}$, Dwi Putri Pratiwi ${ }^{3}$, Lidya Wati ${ }^{4}$, Ratna Wahyu \\ Ningsih $^{5}$, Serianti ${ }^{6}$ \\ Universitas Prima Indonesia, Indonesia
}

\begin{tabular}{l}
\hline Article Info \\
\hline Article history: \\
Received Feb 26, 2021 \\
Revised Mar 10, 2021 \\
Accepted Mar 13, 2021 \\
\hline
\end{tabular}

\section{Keywords:}

Post Partum Mother

Hypnobreastfeeding

Release Of Breast Milk

\begin{abstract}
A woman's breasts that produce breast milk (breast milk) are very good nutritional intake in the process of growth and development of a baby. In ASI (breast milk) contains all the nutrients that are needed by a baby in its perfect growth and development and is the best nutritional intake for the baby. When a baby is sick, breast milk will be a medicine that will save his life. The anxiety experienced by postpartum mothers while breastfeeding their babies will have an impact on the lack of suction in the baby and will affect the lack of milk production so that breast milk is not smooth. Breast milk production will continue to increase for 6 months with an average milk production reaching $700-800 \mathrm{ml}$ and then breast milk production will decrease after more than the first 6 months to 500-600ml. One method that can stimulate milk production is by using the hypnobreastfeeding technique method. The purpose of this study was to determine the effect of hypnobreastfeeding techniques on breastfeeding expenditure in postpartum mothers at Kota Datar Public Health Center. The research design used a preexperimental method with one group pre-test and post-test design. The number of samples in this study were 30 people based on the total population of postpartum mothers who breastfeed their babies with total sampling technique. Aspects of data measurement using observation sheets with bivariate analysis. The results of this study indicate that the respondents experienced an increase in breast milk production. The results of data analysis obtained a value of Z -4.4.889 and Asymp Sig of 0.000 $<0.005$. The conclusion of this study states that there is an effect of hypnobreastfeeding techniques on expressing breastmilk to the mother.
\end{abstract}

This is an open access article under the CC BY-SAlicense.

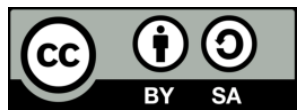

\section{Corresponding Author:}

Parida Hanum,

S1 Kebidanan,

Universitas Prima Indonesia,

Jl. Danau Singkarak, Gg. Madrasah SeiAgul, Kec.Medan Barat, Medan - Sumatera Utara.

Email: Hanumparida06@gmail.com

\section{INTRODUCTION}

Payudara seorang wanita yang menghasilkan air susu merupakan nutrisi yang sangat dibutuhkan oleh bayi dalam masa pertumbuhan dan perkembangannya, didalam (ASI) air susu ibu terkandung semua unsur gizi yang diperlukan oleh bayi dalam pertumbuhan dan perkembangannya yang sempurna dan merupakan asupan nutrisi yang terbaik bagi bayi. Saat bayi dalam keadaan sakit, air susu ibu akan menjadi obat yang akan menyelamatkan jiwanya (United Nations Childrens Fund, Dwi, 2013).

Salah satu kurangnya cakupan ASI adalah terjadinya puting lecet yang parah, bayi rewel, selanjutnya ibu merasa air susu yang keluar tidak mungkin akan cukup untuk memenuhi kebutuhan dan perkembangan bayinya karena ASI masih sedikit. Penyebab minimnya cakupan air susu ibu juga dapat dipengaruhi oleh cara menyusui yang salah. Cara menyusui yang salah akan menyebabkan puting susu ibu 
lecet, ibu enggan menyusui sehingga bayi jarang menyusu. Hal ini dapat menyebabkan kurangnya produksi air susu ibu. (Roesli, 2005).

Implementasi tentang peraturan Menteri Kesehatan Republik Indonesia No.240/Menkes/v/55/2004 tentang pengganti air susu ibu tidak berjalan dengan semestinya. Keadaan ini bisa kita jumpai bahwa dimana ditempat pelayanan kesehatan masih terus menerus dilakukan promosi dan bahkan menjual sendiri susuformulatersebut, bahkan sangat banyak bidan praktek yang kita jumpai sekarang menganjurkan kepada ibu untuk memberikan susu formula pada bayi baru lahir untuk dikonsumsi saat ASI ibu tidak lancar.

Dari hasi "Survey Demografi dan Kesehatan Indonesia, 2007 menyatakan bahkan banyak bayi yang baru lahir di fasilitas kesehatan mendapatkan prelacteal feeding sekitar 70,1\%. (BPS, Macro International, 2008). Kenyataan yang dijumpai dilapangan ternyata masih sangat banyak para ibu yang mengalami masalah dalam pemberian air susu kepada bayinya sehingga membuat ibu tidak bisa memberikan asi eksklusif selama minimal 6 bulan. Padahal seharusnya kondisi menyusui adalah suatu hal/keadaan yang alamiah. Pemeberian edukasi tentang cara menyusui yang benar kepada ibu hamil yang akan menyueui sangat mempengaruhi keberhasilan dalam menyusui. Salah satu cara yang akan dapat membantu dalam mengatasi hambatan dalam pemberian air susu ibu adalah dengan melakukan teknik hypnobreastfeeding.

Teknik hypnobreastfeeding adalah suatu upaya alamiah yang dilakukan dengan menggunakan terapi dengan memberikan kalimat-kalimat sugesti positif supaya pada saat sedang menyusui tidak terjadi hambatan dalam pengeluaran air susu ibu. Dengan menggunakan kalimat-kalimat sugesti positif dan memotivasi pada saat kondisi ibu dalam keadaan tenang dan focus terhadap suatu hal/keadaan hypnosis sehingga air susu yang dihasilkan akan mampu mencukupi kebutuhan pertumbuhan bayinya (Kuswandi, 2009).

Berdasarkan data survey awal yang diperoleh pada bulan Oktober memperlihatkan masih banyak ibu nifas yang tidak menyusui bayinya. Dari hasil wawancara yang dilakukan pada 6 orang ibu, 4 orang diantaranya tidak mau menyusui bayinya disebabkan karena ibu merasa air susunya tidak akan cukup untuk memenuhi kebutuhan bayinya sebab ASI terlalu sedikit, dan 2 ibu lainnya mengalami puting lecet yang sangat parah serta bayi rewel. Dan semua ibu belum mengetahui adanya teknik hypnobreastfeeding. Tujuan pada penelitian ini adalah untuk mengetahui pengaruh teknik hypnobreastfeeding terhadap pengeluaran ASI pada ibu nifas di Puskesmas Kota Datar Tahun 2021.

\section{RESEARCH METHOD}

Penelitian menggunakan metode pre eksperimen. Pada penelitian ini menggunakan rancangan one group pre-test dan post-test design, yaitu pada rancangan ini subyek di observasi sebelum dilakukan intervensi, selanjutnya di observasi lagi setelah dilakukan intervensi. Penelitian ini telah lulus uji etik dengan nomor: 002/KEPK/UNPRI/II/2021. Penelitian ini dilakukan di Puskesmas Kota Datar Tahun 2021. Populasi pada penelitian ini adalah ibu nifas di Puskesmas Kota Datar sebanyak 30 orang. Teknik pengambilan sampel dalam penelitian ini adalah total sampling.

Teknik pengumpulan data menggunakan data primer serta data sekunder. Aspek pengukuran data pada penelitian ini dengan menggunakan lembar observasi, yaitu merupakan alat ukur yang berisi pernyataan yang akan diamati dengan menceklis jika pengeluaran ASI normal dengan banyaknya ASI 500-600 cc, dan digunakan setelah intervensi dilakukannya teknik hypnobreastfeeding terhadap pengeluaran ASI menggunakan uji Wilcoxon.

\section{RESULTS AND ANALYSIS}

\subsection{Hasil}

Adapun hasil penelitian sebagai berikut:

Karakteristik Responden Berdasarkan Usia, Pekerjaan dan Pendidikan di Puskesmas Kota Datar Tahun 2021

\begin{tabular}{|c|c|c|}
\hline Karakteristik & f & $\%$ \\
\hline \multicolumn{3}{|l|}{ Umur } \\
\hline $15-25$ & 18 & 60 \\
\hline $26-35$ & 12 & 40 \\
\hline \multicolumn{3}{|l|}{ Pekejaan } \\
\hline Bekerja & 10 & 67 \\
\hline TidakBekerja & 20 & 33 \\
\hline \multicolumn{3}{|l|}{ Pendidikan } \\
\hline Dasar & 6 & 20 \\
\hline Menengah & 24 & 80 \\
\hline
\end{tabular}

Berdasarkan dari tabel 1 dapat memperlihatkan bahwa hasil karakteristik umur dengan mengunakan 30 responden yaitu mayoritas 15-25 tahun sebanyak 18 orang (60\%), sedangkan minoritas 26-35 tahun 
sebanyak 12 orang (40\%), dan dari hasil karakteristik pekerjaan dengan 30 responden mayoritas tidak bekerja sebanyak 20 orang (33\%), sedangkan minoritas bekerja 10 orang (67\%), serta hasil karakteristik pendidikan dengan 30 responden mayoritas menengah 24 orang $(80 \%)$, dan minoritas dasar 6 orang $(20 \%)$.

Distribusi Frekuensi Pengeluaran ASI pada Ibu Nifas Sebelum (Pre Test) Dilakukan Teknik Hypnobreastfeeding di Puskesmas Kota Datar Tahun 2021

Tabel 2. Pengeluaran ASI sebelum teknik Hypnobreastfeeding terhadap Ibu Nifas ( $\mathrm{n}=30$ )

\begin{tabular}{ccc}
\hline Variabel & f & \% \\
\hline Normal & 3 & 10 \\
\hline Tidak & 27 & 90
\end{tabular}

Tabel 2 pengeluaran ASI pada ibu nifas sebelum (pre test) dilakukan teknik hypnobreastfeeding terhadap 30 responden mayoritas ASI tidak normal yaitu sebanyak 27 orang (90\%), dan minoritas ASI normal sebanyak 3 orang (10\%).

Distribusi Frekuensi Pengeluaran ASI pada Ibu Nifas Sesudah (Post Test) Dilakukan Teknik Hypnobreastfeeding di Puskesmas Kota Datar Tahun 2021

Tabel 3. Pengeluaran ASI sesudah teknik Hypnobreastfeeding terhadap Ibu Nifas $(\mathrm{n}=30)$

\begin{tabular}{ccc}
\hline Variabel & f & \% \\
\hline Normal & 27 & 90 \\
\hline Tidak & 3 & 10 \\
\hline
\end{tabular}

Tabel 3 pengeluaran ASI pada ibu nifas sesudah (post test) dilakukan teknik hypnobreastfeeding dengan 30 responden mayoritas ASI normal sebanyak 27 orang (90\%) dan minoritas ASI tidak normal sebanyak 3 orang $(10 \%)$. Data ini menunjukkan peningkatan pengeluaran ASI pada ibu nifas.

\section{Pengaruh Teknik Hypnobreastfeeding Terhadap Pengeluaran ASI pada Ibu Nifas di Puskesmas Kota Datar Tahun 2021}

Tabel 4. Pengaruh Teknik Hypnobreastfeeding Terhadap Pengeluaran ASI Pada Ibu Nifas

\begin{tabular}{l|c}
\hline \multicolumn{2}{c}{ Test Statistics $^{\mathbf{b}}$} \\
\hline$Z$ & Post_Test - Pre_Test \\
\hline Asymp. Sig. (2-tailed) & $-4.899^{\mathrm{a}}$ \\
\hline a. Based on negative ranks. & .000 \\
\hline b. Wilcoxon Signed Ranks Test & \\
\hline
\end{tabular}

Tabel 4 hasil sebelum dan sesudah teknik hypnobrastfeeding yang dilakukan kepada 30 responden, maka diperoleh hasil menggunakan uji wilcoxon nilai Z -4.4.889 dan Asymp Sig sebesar 0,000<0,005. Data tersebut mendapatkan hasil ada pengaruh teknik hypnobreastfeeding terhadap pengeluaran ASI pada ibu nifas di Puskesmas Kota Datar Tahun 2021.

\subsection{Pembahasan \\ Pengeluaran ASI Sebelum Hypnobreastfeeding}

Berdasarkan hasil penelitian bahwa sebelum dilakukan teknik hypnobreastfeeding kepada ibu nifas mayoritas ASI yang tidak lancar yaitu sebanyak 27 orang (90\%) dan yang normal sebanyak 3 orang (10\%). Kecemasan yang dialami ibu post partum saat menyusui bayinya membuat ibu menghindar dan tidak mau memberikan ASI pada bayinya, akan berdampak terhadap kurangnya isapan pada bayi dan akan berpengaruh terhadap kurangnya produksi ASI sehingga membuat ASI tidak lancar. Ibu yang berhenti menyusui dan tidak memberikan ASI tetapi malah memberikan susu formula kepada bayinya, akan mengakibatkan penurunnan dan kinerja hormon oksitosin dan prolactin yang akan membuat produksi ASI semakin sedikit serta menyebabkan bendungan dan statis ASI (Doko, dkk, 2019).

Hasil penelitian bahwa sebelum dilakukan penelitian mayoritas ASI tidak normal 27 orang (90\%), minoritas normal 3orang (10\%). 40\% wanita Amerika saat ini lebih memilih untuk tidak menyusui bayinya, dan banyak diantaranya mengeluhkan nyeri serta adanya pembengkakan pada payudara. Ini biasanya terjadi pada tiga sampai lima hari post partum (Kartika, 2011).

Salah satu penyebab kurangnya cakupan ASI adalah terjadinya puting lecet yang parah, bayi rewel selanjutnya ibu merasa air susu yang keluar tidak mungkin akan cukup untuk memenuhi kebutuhan pertumbuhan dan perkembangan bayinya karena ASI masih sedikit. Penyebab minimnya cakupan air susu ibu juga dapat dipengaruhi oleh cara menyusui yang salah. Cara menyusui yang salah akan menyebabkan puting susu ibu lecet, ibu enggan menyusui sehingga bayi jarang menyusu. Hal ini dapat menyebabkan kurangnya produksi air susu ibu. (Roesli, 2005). 
Berdasarkan asumsi dari peneliti rasa nyaman serta ketenangan bagi ibu nifas sangat mempengaruhi terhadap pengeluaran ASI, dengan dilakukan teknik hypnobreastfeeding dapat mempengaruhi kerja oksitosin sehingga ibu bisa merasakan rileks pada saat menyusui. Kurangnya asupan, istirahat dan dukungan pada ibu juga mempengaruhi dalam proses pembentukan ASI. Ibu-ibu nifas kurang memahami pentingnya ASI pada bayi sampai usia 2 tahun.

\section{Pengeluaran ASI Sesudah Teknik Hypnobreastfeeding}

Berdasarkan dari hasil penelitian bahwa sesudah dilakukannya hypnobreastfeeding terhadap ibu nifas mayoritas normal yaitu sebanyak 27 orang (90\%), serta yang tidak normal sebanyak 3 orang (10\%). Menurut (Rahmawati, 2017) bahwa produksi ASI akan terus meningkat selama 6 bulan dengan rata-rata produksi ASI mencapai 700-800 ml, kemudian produksi ASI akan menurun setelah lebih dari 6 bulan pertama menjadi 500-600ml.

Teknik hypnobreastfeeding adalah suatu upaya alamiah yang dilakukan dengan menggunakan terapi dengan memberikan kalimat-kalimat sugesti positif supaya pada saat sedang menyusui tidak terjadi hambatan dalam pengeluaran air susu ibu. Dengan menggunakan kalimat- kalimat sugesti positif dan memotivasi pada saat kondisi ibu dalam keadaan tenang dan fokus terhadap suatu hal/keadaan hypnosis sehingga air susu yang dihasilkan akan mampu mencukupi kebutuhan bayinya (Kuswandi, 2009).

Keadaan ini sebenarnya tergantung bagaimana ibu dalam mengendalikan pikiran, sebab jika didalam niat dan pikiran ibu konsisten untuk menyusui bayinya dan selalu memikirkan nilai-nilai yang positif, dukungan suami dan keluarga memungkinkan akan tercapainya dalam pemberian air susu secara eksklusif selama minimal enam bulan tidak akan sulit bagi ibu. Diharapkan dengan teknik hypnobreastfeeding akan memberikan jalan keluar dalam proses pemecahan masalah dalam pengeluaran air susu ibu, serta akan mampu mengatasi hambatan dalam proses menyusui.

Dengan menggunakan teknik hypnobreastfeeding akan dapat menurunkan tingkat kecemasan pada ibu post partum dengan nilai pre eksperimen 8,44 menjadi 1,41 post eksperimen. Sehingga dapat disimpulkan bahwa dengan teknik hypnobreastfeeding akan bisa membuat perasaan ibu menjadi tenang dan nyaman sehingga akan memepercepat proses pengeluaran ASI. (Kusmiyati dan Heni, Yogyakarta).

Hasil penelitian ini menunjukkan bahwa dengan dilakukannya teknik hypnobreastfeeding dapat membuat ibu menjadi lebih tenang dan rileks sehingga meningkatkan hormone oksitosin dan menghasilkan volume air susu pada ibu nifas. Menurut asumsi peneliti teknik hypnobreastfeeding sebaiknya dilakukan sebelum menyusui. Dengan adanya perlakuan teknik hypnobreastfeeding ini membuktikan bahwa penting dilakukan teknik hypnobreastfeeding pada ibu menyusui. Sesuai dengan hasil menggunakan uji wilcoxon menunjukkan hasil yang signifikan nilai Z -4.4.899 dan Asymp Sig sebesar 0,000<0,005 artinya ada pengaruh teknik hypnobreastfeeding terhadap pengeluaran ASI pada ibu nifas di Puskesmas Kota Datar.

\section{CONCLUSION}

Kesimpulan dari penelitian ini adalah Teknik hypnobreastfeeding dapat mempengaruhi banyaknya pengeluaran ASI pada ibu nifas.

\section{REFERENCES}

Aprilia,. 2014. Hypnobreasfeeding, solusi cerdas meningkatkan produksi ASI. http://www.bidankita.com/? = Hypnobreastfeeding\%2C+Solusi +Cerdas +Meningkatkan +Produksi+ASI. Di akses 24 oktober 2017.

UNICEF. 2013. ASI adalah Penyelamat Hidup Paling Murah dan Efektif di Dunia Jakarta: UNICEF; 2013 [cited 201618 Februari]. Available from: http://www.unicef.org/indonesia/id/media_21270.htm.

Walyani,E. S, Endang, P,. 2015. Asuhan Kebidanan Masa Nifas \& Menyusui. Yogyakarta: Pustaka Baru Press.

Wardianti, D.A.D. H. 2016. Pengaruh Hypnobreasfeeding terhadap motivasi ibu menyusui dalam pemberian ASI Ekslusif di kelurahan ngampin, kecamatan ambarawa, kabupaten semarang. http://perpusnwu.web.id/karyailmiah/documents/5669.pdf. di akses tanggal 26 oktober 2017.

WHO. Exclusive breastfeeding [internet]; 2013 [cited: 2013 Nov 23]. Available from: http://www.who.int/nutrition/topics/exclusive_breastfeeding/e/n.

Sugiyono. 2016. Metode Penelitian Kuantitatif Kualitatif Dan R \& D. Bandung: Alfabeta.

Mansyur, N \&Dahlan, K,. 2014. Buku Ajar Asuhan Kebidanan Masa Nifas. Malang: Selaksa Media.

Marliandiani, Y \& Ningrum, N,. 2015. Buku Asuhan Kebidanan Pada Masa Nifas Dan Menyusui. Jakarta: Salemba Medika.

Maritalia, Dewi,. 2012. Asuhan Kebidanan Nifas Dan Menyusui. Yogyakarta: Pustaka Pelajar. Marmi,. 2012. Asuhan Kebidanan Pada Masa Nifas Peurperium Care. Yogyakarta: Pustaka Pelajar. 
Maryunani, Anik,. 2012. Inisiasi Menyusui Dini Asi Ekslusif Dan Manajemen Laktasi. Jakarta: Trans Info Media.

Nugroho, dkk,. 2014. Buku Ajar Asuhan Kebidanan 3 Nifas. Yogyakarta: Nuha Medika.

Nursalam, 2008. Konsep dan penerapan metodologi penelitian ilmu keperawatan pedoman skripsi, tesis dan instrumen penelitian keperawatan edisi 2. Jakarta: Salemba medika. https://books.google.co.id/books?id=62jmbdySq2cC\&pg=PA208\&dq=lembar+observa si+pengeluaran + asi $\& h l=i d \& s a=X \& v e d=0 a h U K E w j k z u r A q d r Y A h U C x b w K H f 26 A a U Q$ $6 A E I K D A A \# v=$ onepage $\& q=$ lembar\%20observasi\%20pengeluaran\%20asi $\& f=$ false. $\mathrm{Di}$ akses tanggal 20 desember 2017.

A rikunto S. 2015. Prosedur Penelitian Suatu Pendekatan Praktik. Jakarta: Rineka Cipta.

Armini, N. W, 2016. Hypnobreasfeeding awali suksesnya ASI Ekslusif. https://www.google.co.id/url? sa $=t \& r c t=j \& q=\&$ esrc $=s \&$ source $=w e b \& c d=1 \& c a d=r j a \& u$ $a c t=8 \& v e d=0$ ahUKEwi77LCVxNnYAhVGG5QKHVxcD6sQFggkMAA\&url=http\%3

A\% 2 F\%2Fejournal.poltekkesdenpasar.ac.id\%2Findex.php $\% 2$ FJSH\%2Farticle $\% 2$ Fdownload\% 2 F10\% 2F32\&usg=A OvVaw2RDih_2sf2maFId4xjP5qY. Di akses tanggal 26 oktober.

Asih, Y \& Risneni,. 2016. Buku Ajar Asuhan Kebidanan Nifas Dan Menyusui. Jakarta: Trans Info Media. Chritian, Aditya. 2016. Hipnosis For Self-Healing. Yokyakarta: Psikopedia.

Evariny,. 2009. Lancar menyusui dengan hipnobreasfeeding. http://www.hypnobirthing.web.id/?p=559 diakses tangggal 26 oktober 2017.

\section{BIOGRAPHIES OF AUTHORS}

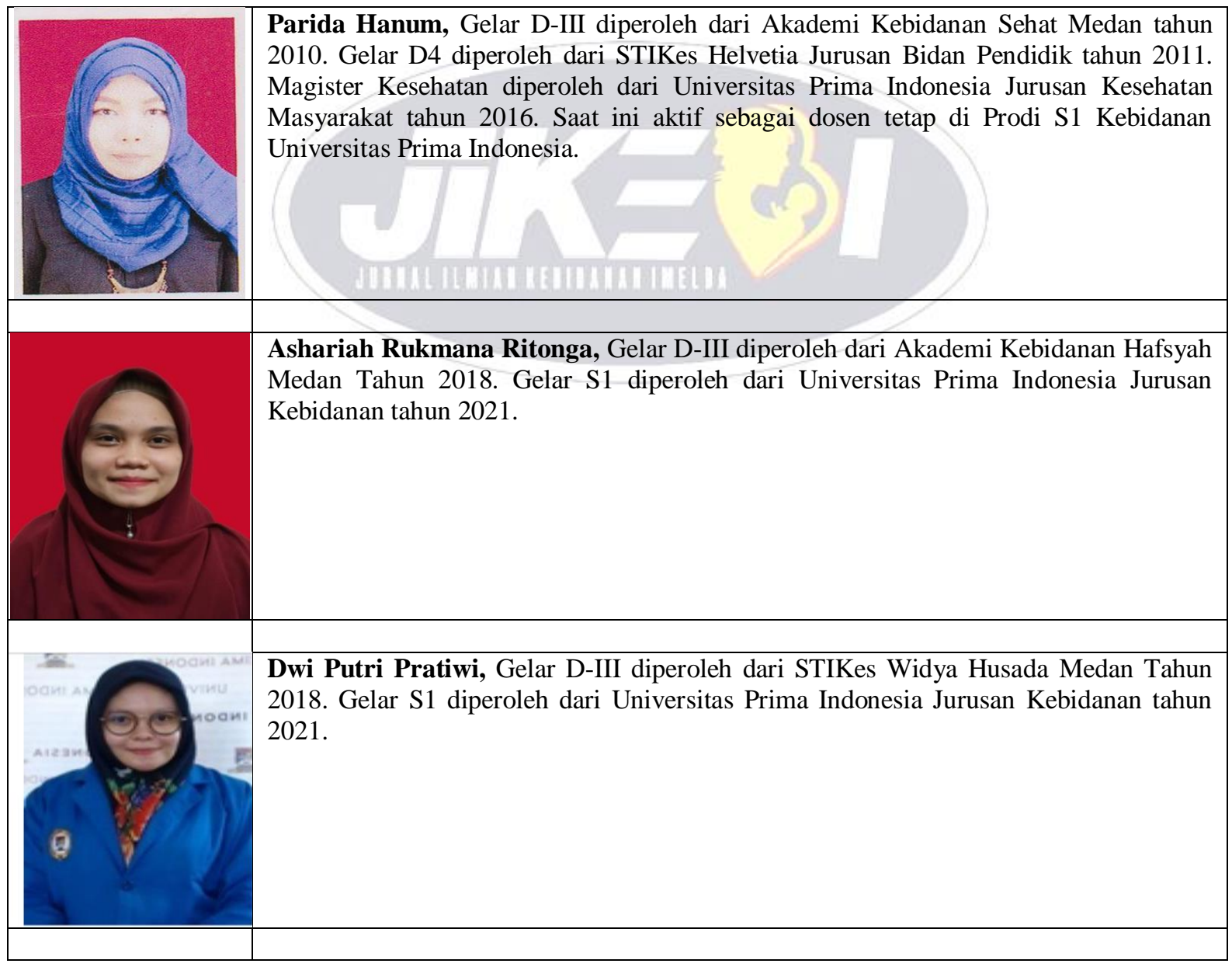




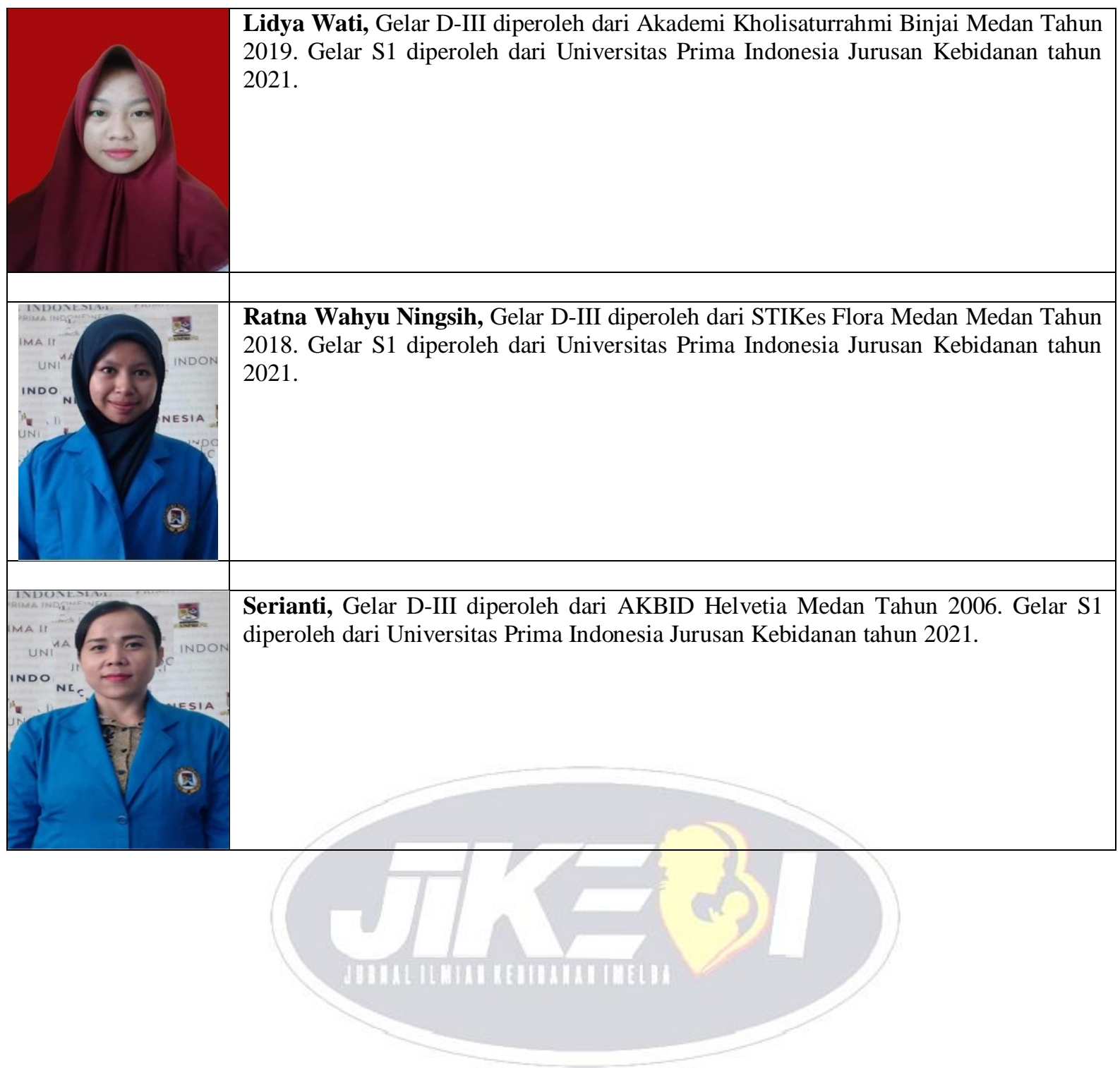

